\title{
Awakening to Space Consciousness and Timeless Transcendent Presence
}

\author{
Christine Jonas-Simpson, RN; PhD'
}

\begin{abstract}
Space consciousness is emerging as significant and necessary for the evolution of humanity according to spiritual teacher, Eckhart Tolle. Through space consciousness people become aware that we are timeless transcendent presence. This awareness is pronounced when with those who are living dying and their close others who are deeply grieving. Space consciousness and transcendent timeless presence in the context of living dying and deeply grieving are explored using nurse theorists' works in dialogue with Tolle's teachings.
\end{abstract}

\section{Keywords \\ dying, grieving, Parse, space consciousness, timeless transcendent presence, Tolle, Watson, Newman, Rogers}

Eckhart Tolle (2008) described space consciousness as sensing "an alert inner stillness in the background while things happen in the foreground" (p. 77). Being alert to the space, the stillness that is in the background, can happen at any time and at any moment; in this column, I will focus on the reverent moments with those who are living dying and deeply grieving. When I read (Tolle, 2003, 2005, 2008) and heard Tolle (2009) speak about space consciousness on a recording from one of his talks, I thought of the moments I have been with persons who were living their dying or deeply grieving, including my own personal experiences of living dying and deeply grieving. These moments heighten my awareness, my alert attention to the present moment and the "stillness in the background." The words "timeless transcendent presence" (Tolle, 2009) also struck me as describing the sense of awareness of who I am in those reverent moments.

According to Tolle (2009), we are the space from which all experiences unfold; we are timeless transcendent presence. He stated that we are already consciousness itself, transcendent timeless consciousness which arises above or beyond conditioned thinking (Tolle, 2009). We are the space in which the various objects arise and this includes thoughts (Tolle). Space consciousness is in contrast to object consciousness where focus is on form, including thought forms (Tolle). So when we are primarily conscious of objects or the world of form, which includes thoughts, we are less aware of the space in which all things arise and this space is essentially who we are. Too often I find myself lost in thought. Even on a gorgeous, sunny day cross-country skiing through the woods I can find myself engaged in object consciousness, thinking about family matters or how many papers I need to mark and transcripts to analyze; however, when I am with persons who are dying or deeply grieving I am acutely aware of the stillness in the background - the space $I$ am. Through contemplation with Tolle's (2003, 2005, 2008, 2009) teachings and nurse theorists' (Newman, 2008; Parse, 1998, 2007; Rogers, 1994; Watson, 2005) writings I am aware that I am timeless transcendent presence which is further characterized by openness to the now moment, mystery, unbounded freedom, and transformation.

In writing this column I struggled with not only the words to choose but also with the structure of the sentences given the topic of space consciousness and timeless transcendent presence, which is formless, when words and sentences are form. To refrain from objectifying the formless using the structure of language is very difficult (Tolle, 2009). Even by simply using the pronoun our when stating "our timeless transcendent presence" creates an object out of presence and thus, I removed the our to get a sense that presence is who we are and not something we have. Also I have refrained from using some of the predominant discourse of death and dying such as end-of-life care, given the view that the opposite of birth is death and life continues on (Tolle, 2003). Also the terms dimension and deeply grieving may connote hierarchical and measurable levels to the reader; however, I am referring to these as qualities. (The hierarchical and particulate connotation of dimension is the very reason Parse (2007) shifted her language from multidimensional to illimitability, which will be described later in the column.) When Tolle (2009) described that we are already the space for the world

\footnotetext{
'Assistant Professor, York University
} 
because we are consciousness itself (which is beyond or deeper than thought), he too acknowledges that high, low, deeper than, are all relative terms and nonexistent when we leave this earth. Tolle $(2003,2005,2008,2009)$ used interchangeably some words which he called pointers, to point to what is, since it is more about sensing the words than understanding them; some of these words are: consciousness, space, timeless transcendent presence, the Now, and awareness. So in this column I am using the words space, consciousness, awareness, and presence to refer to the timeless eternal essence we are which is life itself. I look forward to this dialogue with Tolle's work and nurse theorists' works that I view as gifts to nursing, as we explore timeless transcendent presence and space consciousness in light of living dying and deeply grieving. Tolle's work has been referred to by both Watson (2005) and Newman (2008), and I look forward to furthering this dialogue while contributing to transtheoretical discourse, which Watson and Smith (2005) stated "maintains the integrity of different theories while facilitating and inviting a new discourse for nursing science and spirit" (p. 212). This is my intent.

\section{Opening to the Now}

We enter the room of someone who is dying with alert attention to the present moment. It is with this penetrating attention to the present that we can then enter the Now, which is, according to Tolle (2008), not what happens in the present moment but the space for what is happening in the present moment. The Now is the timeless transcendent space, which is essentially who we are (Tolle, 2009). The possibility of becoming aware of ourselves as timeless transcendent space is never more keenly felt than when we enter the room of someone who is dying. It is felt more keenly as we see that the world of form is ephemeral and eventually dissolves (Tolle, 2009), just as the human form is dissolving before us. Tolle (2009) stated that we cannot find anything lasting in the world of form and that underneath form or beyond it is timeless transcendent presence/consciousness/space - who we are. Knowing this, we can enter the room as simple spacious awareness alert to the now moment rather than as conditioned thinker engaged in object consciousness (Tolle, 2009). Tolle (2008) suggested that we ask ourselves, “Am I aware not only of what is happening at this moment, but also of the Now itself as the living timeless inner space in which everything happens?" (p. 165).

Watson (2005) stated that "in encountering and facing death of self and others, we are in sacred space, touching the mystery of life itself, dwelling in the space of Infinity" ( $p$. 138). This statement opened me to new possibility for understanding the depth of the connection with another who is living dying or deeply grieving. Now, in dialogue with Tolle's works, I wonder if we can say, rather than being in sacred space, or in the space of Infinity (which creates an object out of space), perhaps we are aware that we are sacred space dwelling in Infinity. Initially I, too, conceptualized that we entered a sacred space with those who are living dying or deeply grieving; but now, I understand that we are the space (Tolle, 2009) for nursing practices to exist. This sacred space is experienced with an alert openness to the now moment. It is as if when facing death there is a heightened awareness of life itself, aptly described by Watson (2005) as the moments we face our own humanity.

When we are present with others who are living dying or deeply grieving we do so in the now moment. As we enter the room of someone who is dying or deeply grieving, we can ask ourselves Tolle's simple mantra, "Can I be the space for this?" I believe we can choose to enter the room as a simple spacious presence (Tolle, 2009) with alert attention to the present moment, which helps us become aware of the timeless transcendent space that we are. As we come to be with another who is dying we can do so "as a field of awareness" (Tolle, 2009). Here, we can consider Rogers' (1994) science of unitary human beings, which recognizes the "irreducible human being and its environment, both identified as energy fields" (p. 33). Malinski (2006) clarified that although Rogers identified two fields, they are not separate; this reflects unitary science. I wonder if the energy fields described by Rogers reflect the energy of consciousness - the stillness in the background - the Now - the who we are.

Tolle (2009) described how the present moment is the point of entry into the deeper dimension of the Now. He contended that the Now is really all we have: "There is no time, the Now is all there ever is" (Tolle, 2008, p. 23). In Newman's (2008) book, Transforming Presence, she wrote about the present moment drawing upon Tolle's work:

Reality is the present. When one looks to the future, one moves away from the present experience. Being fully present in the experience of the present is the crux of unity consciousness and is essential to nursing practice/research. (p. 55)

Tolle (2008) wrote, "when you are present, when your attention is fully in the Now, that Presence will flow into and transform what you do" (p. 126). To do this, however, according to Tolle $(2008,2009)$, we must become friendly with the present moment; surrender to it in whatever form it comes and align ourselves with it. Being open to the present moment and surrendering to what might be frees us to be in the Now - the space where life is where we realize and come in touch with our Eternal essence as timeless transcendent presence.

\section{Timeless Transcendent Presence}

If timeless transcendent presence is who we are, then nursing presence with those who are living dying or deeply grieving 
is not something that we do, live, enact, or apply. Nurse theorists provide ways to consider presence with persons who are living dying or deeply grieving that I believe to be true gifts to nursing and humanity. As a nurse prepares to be present with someone who is dying or deeply grieving there is a penetrating shift in focus to the now moment. Parse (1998) wrote:

coming-to-be present through preparation and attention is the all-at-once gentling down and lifting up. It is taking a stand, an unencumbered soft foothold in a tranquil flow, a gentle ease and quiet slowness that moves the nurse and person or group to the tacitexplicit knowing of messages given and taken at many realms of the universe. (p. 72)

This description has helped me in my nursing practice with persons who are living dying and deeply grieving. I wonder if perhaps we become alert to the timeless transcendent presence we are and to the space and stillness of the now moment as we take an "unencumbered soft foothold in a tranquil flow" (Parse, 1998, p. 72), where a "gentle ease and quiet slowness" (p. 72) is lived with another. Parse (1998) also described living true presence as the art of humanbecoming. It is "a special way of 'being with' in which the nurse is attentive to moment to moment changes in meaning as she or he bears witness to the person's own living of value priorities" (p. 71). Living true presence as defined by Parse has been critical in my nursing practice with persons living dying (Jonas, 1995) and deeply grieving (Jonas-Simpson \& McMahon, 2005). I am now wondering in this dialogue if true presence is not something we live but rather, is essentially who we are. As timeless transcendent space, we are "attentive to the moment to moment changes" and experience the "loving, nonjudgmental, free-flowing attentiveness" (Parse, 1998, p. 71).

Watson (2005) described an evolving perspective of the environment and invited nurses to "consider the practitioner and their evolved caring consciousness, presence, intentionality, heart-centred foci, and so forth, as the environment [italics in original]" (p. 94). A series of questions originally posed by a Rogerian scholar (Quinn, 1992) were adapted to reflect this evolved conceptualization of environment. Two of these questions are: "If I am the environment, how can I be a more caring-healing environment?" and, "How can I become a safe space, a sacred vessel, a holy space for this client and his/her soul's inner healing journey?" (Watson, 2005 , p. 94). Considering nurses as the environment-or, I would suggest, space-is exciting. I wonder if we could also consider the following ideas further: If we are timeless transcendent space that is our eternal essence or consciousness, then how can we "be a more caring-healing environment," or "become a safe space, a scared vessel, a holy space," when in essence, transcendent presence is already always present (as it is who we are and it in itself is sacred and holy as it is emerging from the Infinite)? Tolle (2009) stated, "we are already the space for the world, we are consciousness itself."

Watson (2005) stated that when we see the practitionerclient field as one entity, "connecting with infinity of universal field of energy/spirit/love," perhaps we can better grasp the extant caring theories and findings reported by Smith (1999), two of these being:

Caring is a way of experiencing the Infinite (by working from heart-centre and working toward one's own evolving consciousness, becoming more and more aware of the presence of infinity Love/spirit/universal energy);

Caring is a way of inviting creative emergence (by practitioner holding sacred/holy space through intentional uses of heart energetics, consciousness of caring and love, where by the mystery, infinity can enter into the now). (Smith, as cited in Watson, 2005, p. 95)

Viewing these findings in light of the evolving practitioner, Watson's stated, "we can literally become the healing environment" (p. 95). I wonder now in the context of this dialogue: If we are timeless transcendent consciousness itself, how can consciousness evolve? And, if the now is mystery, the Infinite, how can mystery and the Infinite enter the now? Regardless, these words reveal shifting awareness to the formless timeless transcendent presence as who we are, which connects us to mystery - the Eternal - the Infinite.

\section{Mystery - The Eternal - The Infinite}

When death is denied, life loses its depth. The possibility of knowing who we are beyond name and form, the dimension of the transcendent, disappears from our lives because death is the opening into that dimension. (Tolle, 2003, p. 106)

All forms are ephemeral and impermanent. All life forms and all forms eventually die or disintegrate. Human life forms die, and yet life, "the dimension of the transcendent" (Tolle, 2003), continues. Eternal essence is paradoxically housed in a human life form that is subject to time and will eventually dissolve. We bear witness to this human form dissolving as we are with those who are living dying and yet, we also bear witness to the timeless eternal being radiating through. Tolle (2003) stated that "some people become deeply peaceful and almost luminous just before they die, as if something is shining through the dissolving form" (p. 111).

The nurse prepares to be open to the moment that is unknown and mysterious. Being with persons who are living 
their dying or deeply grieving opens us to the sacred, to wonder, and to the mystery of our lives beyond form. Mystery is a postulate of humanbecoming and is defined by Parse (2007) as "the unexplainable, that which cannot be completely known unequivocally. It is a puzzlement, an impenetrable" (p. 309). Parse said that "no one or no thing is completely knowable; there is always the unfathomable with the indivisible, unpredictable, everchanging humanuniverse" (p. 309). She quoted Marcel, who stated, "mystery is itself like a river, which flows into the Eternal, as into the sea" (p. 309). Watson (2005) said that "in encountering and facing death of self and others, we are in sacred space, touching the mystery of life itself, dwelling in the space of Infinity" (p. 138). The mystery of our essence that transcends death is also evident in Todaro-Franceschi's (2006) study in which she explored the experience of synchronicity, which she defined as meaningful coincidence related to dead loved ones. From a Rogerian perspective, Todaro-Franceshci views death in a pandimensional universe as "a change in cosmic address" (p. 159) rather than an ending. Being with those who are dying and deeply grieving opens us to the dimension of the transcendent - our eternal essence - which is the ultimate mystery. Becoming aware of our eternal essence in the now moment with those who are living dying or deeply grieving is a gift for the person and for the nurse as well.

Newman (2008) wrote that "the in-betweeness of presence is seen as a mysterious force that represents a fundamental reality of mutuality" (p. 53). Is this mysterious force the now moment that opens us to the grace and unconditional love of consciousness itself? Mitchell and Bunkers (2003) described the abyss, the place where many fear to be with others who are deeply suffering or in pain, such as those who are dying or deeply grieving. It was concluded that, "the mystery of the abyss is that love transcends and changes risk in ways that transform persons who engage and abide here" (p. 123). Lee and Pilkington (1999) similarly stated that "[while] bearing witness to another's end-of-life passage, many powerful and wondrous moments occur in palliative practice" (p. 412). These wondrous moments experienced with another are transformative. Newman stated that "what is involved in transforming presence is becoming one with the client [italics and bold in original]" (p. 56). As Tolle (2005) stated, "in the stillness of Presence, you can sense the formless essence in yourself and in the other as one. Knowing the oneness of yourself and the other is true love, true care, true compassion" (p. 177).

\section{Unbounded Freedom}

Awareness of timeless transcendent space is experienced as unbounded freedom with those who are living dying or deeply grieving. The space is unbounded by time and place and characterized by openness. Openness is a postulate of Rogers' science of unitary human beings, which Malinksi
(2006) further described as follows: "In an open universe, there are no boundaries other than perceptual ones. Therefore, human and environment are not separated by boundaries" (p. 163). Parse's (2007) postulate of illimitability can be drawn upon here for further exploration. Illimitabilty is "the indivisible unbounded knowing extended to infinity, the all-at-once remembering and prospecting with the moment" (p. 308). The invisible unbounded knowing is felt when the nurse, as presence bears witness to another's transition from this realm to the next. The knowing is mutually shared and acknowledged with a knowing look, touch, or gesture that penetrates the infinite and opens to the dimension of transcendence.

After the earthquake in Haiti, many of us were reeling with the images of devastation, pain, loss, and raw grieving. At the same time, in my undergraduate classes we were studying the concept of true presence (Parse, 1998). I invited students to live in silent immersion (Parse, 1998) with those persons touched by the Haiti earthquake. All agreed. I projected photos of persons from Haiti onto the screen and then read the definition of silent immersion prior to the minute of silence:

Silent immersion is true presence without words, just "being with" through immediate engaging in the presence of another or through imagination with a grounding in the intention to bear witness to the other's becoming. The intention is felt and disclosed at many realms of the universe. (Parse, 1998, p. 73)

For 1 minute, we sat as collective timeless transcendent space in silent immersion with persons from Haiti and around the world. A pin could drop and be heard. I felt a love from and for my students and all humanity in that moment along with the power of hope. We sat as spacious presence with alert attention and awareness of persons and families in Haiti as well as their families and friends from around the world who were both grieving and hoping all-at-once. With the Internet and multimedia access global experiences of grieving and loss are emerging with more and more frequency, whether it is witnessing a figure skater compete at the Olympics after the sudden death of her mother, or whether another country is left in ruins after a natural tragedy or persistent war. That we can offer ourselves as timeless unbounded presence through simple alert attention (Tolle, 2009) is a gift to others and ourselves.

\section{Transformation}

Living as timeless transcendent presence with another who is living dying or deeply grieving is transforming. We are forever changed in these moments of deep connection, where unconditional love is felt and experienced in the space we hold as the who we are. Kübler-Ross (Kübler-Ross \& Gold, 
1997) came to know that the only way healing was possible was through unconditional love. To be this space with another is a tremendous privilege. We are touched by the mystery of life itself and thus, the Infinite, the Eternal (Watson, 2005). It goes beyond understanding and opens to the possibility that Kübler-Ross came to at the end of her career when she said, "the only inconvertible fact of my work is the importance of life" (Kübler-Ross \& Gold, 1997, p. 5). She is also quoted as saying that we must "learn to get in touch with the silence" (Kübler-Ross, n.d.). Silence is where life can be felt. Tolle (2003) said that "death is not the opposite of life. Life has no opposite. The opposite of death is birth. Life is eternal" (p.103). So then, paradoxically, the space where we are with those living their dying and deeply grieving is touching the most fundamental pristine experience of life itself. We become aware of our eternal essence as sacred space with others and thus, the space of Infinity where there is no death.

However, if we are timeless transcendent presence or consciousness or space, then how can we transform, and how can it be possible to expand our consciousness? According to Tolle (2008):

Consciousness is already conscious. It is the unmanifested, the eternal. The universe, however, is only gradually becoming conscious. Consciousness itself is timeless and therefore does not evolve. It was never born and does not die.

When consciousness becomes the manifested universe, it appears to be subject to time and to undergo an evolutionary process. (p. 131)

Perhaps rather than expanding our consciousness, we are becoming more fully aware that we are consciousness, the space or stillness in the background, particularly in the context of living dying or deeply grieving. Or perhaps, when we refer to transformation and expanding consciousness, we mean human transformation, human evolving, or human expansion, since the human of human being is subject to an evolutionary process (Tolle, 2005, 2008) and has the potential to transform, expand, or evolve; whereas the being of human being - our essential Being (Tolle, 2009), is already evolved, as it is consciousness itself. Tolle (2005) stated that being "is found in the still, alert presence of Consciousness itself, the Consciousness that you are. Human is form. Being is formless. Human and Being are not separate but interwoven" (p. 105). As Tolle (2008) stated, space consciousness is necessary for the evolution of humanity.

Newman (2008) drew on de Quincey, who stated that "there is something about the nature of consciousness ...that requires the presence of the other as another subject which can acknowledge my being" (p. 52). Is this what Tolle (2008) referred to as consciousness becoming conscious of itself; or, when we are "conscious of being conscious" (p. 77)? Is this what happens when we are with a person whose form is dissolving and whose light is shining through? Are we, as Watson (2005) stated, "touching the mystery of life itself, dwelling in the space of Infinity" (p. 138)?

\section{Conclusions}

To consider that we are timeless transcendent presence, an alert field of awareness of spacious attention with those who are living dying and deeply grieving, is a transformational shift that was discovered in dialogue with nurse theorists works' and with Tolle's $(2003,2005,2008,2009)$ teachings. As we continue to engage in space consciousness we may wish to remember Tolle's mantra, "Can I be the space for this?" The answer, of course, is "yes!" As Tolle (2009) stated, we are already the space for this. The question is: Are we aware of it? For me, becoming aware that we are the timeless transcendent presence or space with those who are living dying or deeply grieving through this dialogue has been a gift. Being open to the now moment, sensing unbounded freedom, mystery, and the transformation of humanity is inspiring. The question, "Can I be the space for this? " opens me to space consciousness each and every moment. I feel gratitude to nurse theorists Rosemarie Rizzo Parse, Margaret Newman, Martha E. Rogers, and Jean Watson and to spiritual teacher Eckhart Tolle for their work, and for this opportunity to engage in dialogue with their work. This is only the beginning of the dialogue and one I hope continues as we further transtheoretical discourse on our understanding of space consciousness and the who we are - timeless transcendent presence.

\section{Declaration of Conflicting Interests}

The author declares that she does not have any conflict of interest.

\section{References}

Jonas, C. M. (1995). True presence through music for persons living their dying. In R. R. Parse (Ed.), Illuminations: The human becoming theory in practice and research (pp. 97-104). New York: National League for Nursing Press.

Jonas-Simpson, C., \& McMahon, E. (2005). The language of loss when a baby dies prior to birth: Cocreating human experience. Nursing Science Quarterly, 18, 124-130.

Kübler-Ross, E. (no date). Quotes. Elizabeth Kübler-Ross Foundation. Retrieved from http://www.ekrfoundation.org//education. html

Kübler-Ross, E., \& Gold, T. (1997). The wheel of life: A memoir of living and dying. New York: Touchstone.

Kübler-Ross, E., \& Kessler, D. (2000). Life lessons: Two experts on death and dying teach us about the mysteries of life and living. New York: Touchstone.

Lee, O. J., \& Pilkington, F. B. (1999). Practice with persons living their dying: A view from the human becoming perspective. Nursing Science Quarterly, 12, 324-328. 
Malinski, V. (2006). Martha E. Rogers' science of unitary human beings. In M. Parker (Ed.), Nursing theories and nursing practice (2nd ed., pp. 160-166). Philadelphia: F. A. Davis.

Mitchell, G. J., \& Bunkers, S. S. (2003). Engaging the abyss: A mis-take of opportunity. Nursing Science Quarterly, 16, 121-125.

Newman, M. (2008). Transforming presence: The difference that nursing makes. Philadelphia: F. A. Davis Co.

Parse, R. R. (1998). The humanbecoming school of thought: A perspective for nurses and other health professionals. Thousand Oaks, CA: Sage.

Parse, R. R. (2007). The humanbecoming school of thought in 2050. Nursing Science Quarterly, 20, 308-311.

Quinn, J. F. (1992). Holding sacred space. The nurse as healing environment. Holistic Nursing Practice, 6(4), 26-35.

Smith, M. (1999). Caring and the science of unitary human beings. Advances in Nursing Science, 21(4), 14-28.
Rogers, M. E. (1994). The science of unitary human beings: Current perspectives. Nursing Science Quarterly, 7, 33-35.

Todaro-Franceschi, V. (2006). Synchronicity related to dead loved ones as a natural healing modality. Spirituality and Health International, 7, 151-161.

Tolle, E. (2003). Stillness speaks. Vancouver, BC: Namaste Publishing.

Tolle, E. (2005). A new earth: Awakening to your life's purpose. New York: Plume.

Tolle, E. (2008). Oneness with all life. New York: Dutton.

Tolle, E. (2009). Awakening in the now [DVD production]. Boulder, CO: Sounds True.

Watson, J. (2005). Caring science as sacred science. Philadelphia: F. A. Davis.

Watson, J., \& Smith, M. C. (2005). A transtheoretical discourse for nursing knowledge development. In J. Watson (Ed.), Caring science as sacred science (pp. 211-230). Philadelphia: F. A. Davis. 